\title{
Continuous electrocardiographic recording during exercise in young male diabetics A computer study
}

\author{
I. W. Campbell, S. McGarry, D. N. Smith, J. M. Neilson, and B. F. Clarke
}

From the Diabetic and Dietetic Department, The Royal Infirmary, Edinburgh, and Department of Medical Physics, University of Edinburgh

Forty selected young patients with diabetes of medium to long duration and 26 control subjects without clinical evidence of ischaemic heart disease were studied using a new and sensitive technique of electrocardiographic recording during exercise with continuous computation of the time course of the ST-T segment changes to detect possible early ST depression indicative of ischaemia.

Although no such evidence was found, significant differences in the diabetics were observed in the heart rate and ST-T segment, the latter changes having not been previously reported but which may be attributed to ischaemia or alternatively to autonomic neuropathy in the 'presymptomatic' phase.

Incipient ischaemic heart disease in asymptomatic subjects may be detected by electrocardiography after exercise (Master, Friedman, and Dack, 1942). Continuous electrocardiographic recording during exercise is possibly an even more sensitive method for detecting incipient ischaemic heart disease ( $\mathrm{Yu}$ and Soffer, 1952) especially using more recent techniques such as radioelectrocardiography (Bellet et al., 1962) or computer analysis (Bruce et al., 1966). A further improvement of the latter has been described by Neilson, Davies, and Kitchin (I968) with continuous computer quantitation during exercise of the time course of the ST segment (Davies et al., 197I) and T wave amplitude changes (Kitchin and Neilson, 1972).

While the increased prevalence of symptomatic ischaemic heart disease in younger diabetics of moderate to long duration is well recognized (Bradley and Partamian, 1965), there are at present few studies of the early detection of ischaemic heart disease while still in the asymptomatic phase in such diabetics. The aim of this study was to examine a group of selected young insulin-dependent male diabetics with no clinical evidence of ischaemic heart disease, recording with a special hybrid computer (Neilson et al., 1968) the electrocardiographic waveform changes continuously before, during, and after exercise.

Received I6 May 1974.

\section{Patients and methods}

Forty young insulin-dependent male diabetics aged 20 to 34 years (mean age 29.4 years) and of duration 5 to 27 years (mean duration 12.5 years) were selected for study. All were within Io per cent of their standard body weight and were normotensive (diastolic BP less than 90 mmHg (12 kPa); systolic BP less than $150 \mathrm{mmHg}$ $(20 \mathrm{kPa})$ ). None had clinical evidence of ischaemic heart disease as detected by a history of angina (Rose and Blackburn, 1968), standard exercise electrocardiography (Master and Rosenfeld, 196r), or coronary artery intimal calcification, as detected by radiological screening (Oliver et al., 1964), and all had fasting plasma cholesterol and triglyceride levels within the normal range. Details of the patients' age, duration of diabetes, and specific diabetic complications are shown in Table I.

The 26 age-matched male control subjects likewise had no clinical evidence of ischaemic heart disease and all were normotensive, the conditions of exercise electrocardiography being identical in the two groups.

All subjects, diabetic and control, were studied in the post-absorptive state and at normal room temperature $\left(16-19^{\circ} \mathrm{C}\right)$, and exercised on a motor-driven treadmill. Each patient was studied over four 5-minute periods:

Period $I$ - a control resting period with the subject standing erect on the treadmill.

Period 2 - a first period of exercise walking on the level at 3.2 miles per hour.

Period 3-a second and more severe period of exercise walking at the same speed at a Io per cent tilt on the treadmill following immediately on period 2. 
TABLE I Groups, duration, age, and complications of the diabetic patients

\begin{tabular}{|c|c|c|c|c|c|c|c|}
\hline \multirow{2}{*}{$\begin{array}{l}\text { Groups and duration of } \\
\text { diabetes }(y r)\end{array}$} & \multirow{2}{*}{$\begin{array}{l}\text { No. of } \\
\text { subjects }\end{array}$} & \multirow{2}{*}{$\begin{array}{l}\text { Age range } \\
(y r)\end{array}$} & \multirow{2}{*}{$\begin{array}{l}\text { No. of diabetic } \\
\text { patients with } \\
\text { complications }\end{array}$} & \multicolumn{4}{|c|}{ Complications } \\
\hline & & & & $\begin{array}{l}\text { Retino- } \\
\text { pathy }\end{array}$ & $\begin{array}{l}\text { Nephro- } \\
\text { pathy }\end{array}$ & $\begin{array}{l}\text { Neuro- } \\
\text { pathy }\end{array}$ & $\begin{array}{l}\text { Intermittent } \\
\text { claudication }\end{array}$ \\
\hline $\begin{array}{l}\text { All diabetics }(5-27, \\
\text { mean } 12.5)\end{array}$ & 40 & $\begin{array}{l}20-34 \\
\text { (mean 29.4) }\end{array}$ & 14 & 12 & 5 & 2 & 3 \\
\hline $\begin{array}{l}\text { Long-standing diabetics } \\
\quad(15+, \text { mean } 20.7)\end{array}$ & 12 & $\begin{array}{l}26-34 \\
\text { (mean 31.8) }\end{array}$ & 9 & 8 & $3^{\star}$ & $\mathbf{I}$ & 2 \\
\hline
\end{tabular}

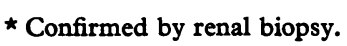

Period 4-a recovery period still standing on the treadmill.

A single electrocardiographic lead was employed corresponding to position $\mathrm{CR}_{5}$, and the details of the improved technique of continuous recording on magnetic tape of the amplified electrocardiographic signal has been previously described (Kitchin and Neilson, 1972). The computer was programmed to correct automatically for shortening of the QT interval with increases in heart rate, and during the analysis the electrocardiogram was visually monitored to ensure that the ST segment sampling point (vide infra) never became involved in a widening $Q R S$ wave. The magnetic tapes were analysed using a special purpose hybrid computer (Neilson et al., 1968) to derive continuous analogue outputs of: 1 ) the heart rate, 2) the deviation of the ST segment taking a point $24 \mathrm{~ms}$ after the J point, and 3) the amplitude of the T wave (in both 2 and 3 the isoelectric line was assumed to be represented by the PR segment of each successive complex).

The Fig. shows a typical trace obtained. Sixty-six similar traces representing the time course of heart rate, ST segment, and T wave amplitude were examined in the 40 diabetic and 26 control subjects. Though there was considerable variation in the patterns of the traces in all subjects studied, it was nevertheless possible to distinguish visually between those of the control and those of the diabetic groups. From the tracings measurements were made of the changes in heart rate, ST seg- ment deviation, and apex $\mathrm{T}$ wave amplitude from their values during the 5-minute pre-exercise control period. In particular, the initial change in heart rate at the onset of exercise (AI), at the end of exercise (BI), and the residual change after 5 minutes recovery $(\mathrm{Cr})$ were noted. Likewise, changes in the ST segment $\left(\mathrm{A}_{2}, \mathrm{B2}\right.$, $C_{2}$ ) and apex $T$ wave amplitude $\left(A_{3}, B_{3}, C_{3}\right)$ from their mean resting levels were measured at the onset and end of exercise and 5 minutes after exercise.

The diabetic patients were studied in two groups: all diabetics (40 patients) and the long-standing diabetics of 15 or more years' duration (12 patients).

\section{Results}

\section{Heart rate change (Table 2)}

The resting heart rates in the diabetics were significantly higher than those in the control group. No significant differences occurred in the increases in heart rate between the diabetics and the controls either at the start or at the end of exercise. During the recovery period, however, the diabetics showed a significantly slower return to the pre-exercise heart rate than the controls.

\section{ST segment deviation (Table 3)}

The ST segment depression both at the onset and at the end of exercise was significantly less in the

TABLE 2 Heart rate change

\begin{tabular}{|c|c|c|c|c|c|c|c|}
\hline $\begin{array}{l}\text { Group } \\
\text { (No. of subjects) }\end{array}$ & $\begin{array}{l}\text { Mean resting } \\
\text { heart rate } \\
\text { (beats } / \text { min) }\end{array}$ & $\begin{array}{l}\text { SD } \\
\text { (beats/min) }\end{array}$ & $P \star$ & $\begin{array}{l}\text { Mean change } \\
\text { in heart rate } \\
\text { between rest } \\
\text { and start of } \\
\text { exercise } \\
\text { (beats/min) }\end{array}$ & $S D$ & $P \star$ & $\begin{array}{l}\text { Mean change in } \\
\text { heart rate } \\
\text { between rest } \\
\text { and end of } \\
\text { exercise } \\
\text { (beats/min) }\end{array}$ \\
\hline Controls (26) & 84 & I I.4 & - & +20 & 8.2 & $\overline{\mathrm{NS}}$ & +46 \\
\hline $\begin{array}{l}\text { All diabetics (40) } \\
\text { Long-standing diabetics }\end{array}$ & 94 & 14.4 & $<0.0025$ & +24 & 10.3 & $\begin{array}{c}<0.1 \\
\text { NS }\end{array}$ & +45 \\
\hline (I2) & 92 & 12.3 & $<0.05$ & +25 & 9.3 & $<0.1$ & +48 \\
\hline
\end{tabular}

^ Significance (Student's $t$ test) between diabetic groups and matched controls. 
TABLE $3 S T$ segment deviation from resting level

\begin{tabular}{|c|c|c|c|c|c|c|c|c|c|}
\hline $\begin{array}{l}\text { Group } \\
\text { (No. of subjects) }\end{array}$ & $\begin{array}{l}\text { Mean initial } \\
\text { deviation of } \\
S T \text { segment } \\
(m V)\end{array}$ & $S D$ & $P^{\star}$ & $\begin{array}{l}\text { Mean deviation } \\
\text { of } S T \\
\text { segment at } \\
\text { end of exercise } \\
(m V)\end{array}$ & $S D$ & $P \star$ & $\begin{array}{l}\text { Mean deviation } \\
\text { of ST segment } \\
5 \text { minutes after } \\
\text { exercise } \\
(m V)\end{array}$ & $S D$ & $P^{\star}$ \\
\hline Controls (26) & -0.049 & 0.036 & - & -0.130 & 0.046 & - & -0.017 & 0.023 & - \\
\hline $\begin{array}{l}\text { All diabetics ( } 40 \text { ) } \\
\text { Long-standing }\end{array}$ & -0.029 & 0.031 & $<0.01$ & -0.102 & 0.058 & $\begin{array}{c}<0.025 \\
\text { NS }\end{array}$ & -0.044 & 0.035 & $<0.001$ \\
\hline diabetics (12) & -0.026 & 0.041 & $<0.05$ & -0.100 & 0.071 & $<0.1$ & -0.039 & 0.039 & $<0.025$ \\
\hline
\end{tabular}

* Significance (Student's t test) between diabetic groups and matched control group.

diabetics (but not in the long-standing diabetics at the end of exercise), and after exercise all the diabetic patients showed a slower return of the ST segment to the resting level.

T wave amplitude changes (Table 4).

No significant change was observed in the depression of the apex of the $T$ wave at the start of exercise between the diabetic and control subjects. The $T$ wave depression at the end of exercise was significantly less in the diabetic subjects, but during the recovery period the $T$ wave in the diabetics tended to remain depressed in contrast to the rapid recovery of the $T$ wave height, often to a level exceeding that at rest, in the controls.

\section{Discussion}

The finding of increased resting heart rate in diabetic subjects compared with controls has been previously reported (Ewing et al., 1974; Wheeler and Watkins, 1973), and it has been suggested that this may reflect impairment of vagal innervation of the heart as a consequence of diabetic autonomic neuropathy (Wheeler and Watkins, 1973). The heart rate response during exercise, however, was similar

\begin{tabular}{lllll}
\hline$S D$ & $P^{\star}$ & $\begin{array}{l}\text { Mean change in } \\
\text { heart rate between } \\
\text { rest and 5 minutes } \\
\text { after exercise } \\
\text { (beats/min) }\end{array}$ & & \\
& & & & \\
\hline 9.8 & - & +0.19 & $5.8 \mathrm{I}$ & - \\
$\mathrm{II.2}$ & $\begin{array}{c}\mathrm{NS} \\
<0.45\end{array}$ & +12 & $7.1 \mathrm{I}$ & $<0.001$ \\
$\mathrm{NS}$ & $<0.3$ & +14.7 & 7.43 & $<0.00 \mathrm{I}$ \\
\hline
\end{tabular}

in both diabetic and control groups, which may be explained by the fact that exercise overcomes the normal effect of the vagus on the sinus node (Schaefer and Haas, 1962). The reason for the delayed return of the heart rate after exercise in the diabetics is not clear, but may be because of lack of restoration of normal vagal tone.
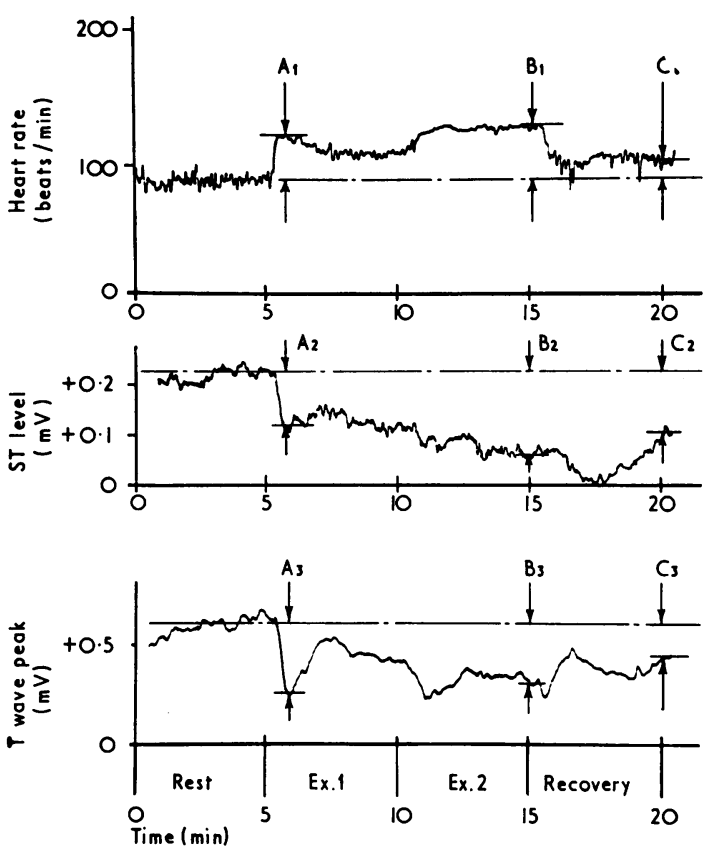

FIG. Typical trace showing changes in heart rate, $S T$ segment, and $T$ wave amplitudes before, during, and after exercise. $A_{1}, A_{2}, A_{3}$ indicate the initial change in heart rate, $S T$ segment, and $T$ wave peak at 15 to 30 seconds after the onset of exercise. $B 1, B 2$, $B_{3}$ indicate the respective changes immediately at the end of exercise, and $C_{1}, C_{2}, C_{3}$ the residual changes exactly 5 minutes after exercise. 
TABLE 4 Change in $T$ wave amplitude from resting level

\begin{tabular}{|c|c|c|c|c|c|c|c|c|c|}
\hline $\begin{array}{l}\text { Group } \\
\text { (No. of subjects) }\end{array}$ & $\begin{array}{l}\text { Mean initial } \\
\text { change in } \\
\text { apex } T \text { wave } \\
\text { amplitude } \\
(m V)\end{array}$ & $S D$ & $P \star$ & $\begin{array}{l}\text { Mean change } \\
\text { in apex } T \\
\text { wave amplitude } \\
\text { at end of } \\
\text { exercise } \\
(m V)\end{array}$ & $S D$ & $P \star$ & $\begin{array}{l}\text { Mean change } \\
\text { in apex } T \\
\text { wave amplitude } \\
5 \text { minutes } \\
\text { after exercise } \\
(\mathrm{mV})\end{array}$ & $S D$ & $P \star$ \\
\hline $\begin{array}{l}\text { Controls (26) } \\
\text { All diabetics }\end{array}$ & -0.059 & 0.13 & - $\mathrm{NS}$ & -0.248 & 0.16 & - & +0.076 & 0.112 & - \\
\hline $\begin{array}{l}\text { (40) } \\
\text { Long-standing }\end{array}$ & -0.020 & 0.29 & $\begin{array}{c}<0.1 \\
\text { NS }\end{array}$ & -0.103 & 0.15 & $<0.0025$ & -0.046 & 0.132 & $<0.001$ \\
\hline diabetics (12) & -0.006 & 0.12 & $<0.1$ & -0.073 & 0.16 & $<0.005$ & -0.034 & 0.121 & $<0.005$ \\
\hline
\end{tabular}

* Significance (Student's $t$ test) between diabetic groups and matched control group.

It was expected that the continuous electrocardiographic recording during exercise might reveal ST segment depression indicative of myocardial ischae$\mathrm{mia}$ in the diabetics, particularly the longer duration group. It has been shown that using this same technique patients with impaired coronary blood flow have increased depression of the ST segment during exercise compared with controls (Kitchin and Neilson, 1972), and it is surprising that the ST depression was significantly less in the diabetics than in our control subjects. The exercise electrocardiographic studies of Karlefors (1966) in male diabetics before and after but not during exercise showed a greater ST depression in the postexercise period in the diabetics compared with the controls. Our observations of the post-exercise ST segment depression may therefore be similar, but we have observed further that during exercise the controls had in fact greater ST depression than the diabetics. Immediately after exercise the controls, however, showed a rapid return of the ST depression to normal whereas the ST segment in the diabetics tended to remain depressed.

The normal pattern of $T$ wave change in response to exercise is depression of the apex of the wave followed by a sharp rise to normal levels or even greater immediately after exercise (Kitchin and Neilson, 1972). In the diabetics after the initial minimal depression of the $T$ wave at the start of exercise, similar to that in the controls, there was significantly less depression at the end of exercise and a tendency to remain depressed in the recovery period. The diabetics thus tended to have a 'fixed' $T$ wave in response to exercise. The vagus probably augments the height of the $T$ wave (Schaefer and Haas, 1962) and the findings in the diabetic group, particularly in the recovery period, might, therefore, be partly explained by an impairment of normal vagal parasympathetic tone.
The present study has failed to demonstrate any early 'conventional' ischaemic changes in a group of selected diabetics as judged at this level of exercise by this more sensitive technique of continuous electrocardiographic recording during exercise, but that the ST-T segment abnormalities may nevertheless be partly attributable to ischaemia or metabolic effects, such as changes in lactate concentration during exercise, cannot be entirely discounted. It has highlighted previously unreported changes involving particularly the ST-T segment during exercise in diabetics, the precise significance of which is not clear, but which may be caused by autonomic dysfunction involving vagal innervation of the heart and may, therefore, indicate diabetic autonomic neuropathy in the 'presymptomatic' phase.

The computer used in this study was developed with the support of a grant from the Scottish Hospitals' Endowment Research Trust. I.W.C. was in receipt of a research grant from Pfizer (Europe) Ltd. We would like to thank Professor K. W. Donald for use of facilities in the Department of Medicine, The Royal Infirmary.

\section{References}

Bellet, S., Eliakim, M., Deliyiannis, S., and LaVan, D. (1962). Radioelectrocardiography during exercise in patients with angina pectoris. Circulation, $25,5$.

Bradley, R. F., and Partamian, J. O. (1965). Coronary heart disease in the diabetic patient. Medical Clinics of North America, 49, 1093.

Bruce, R. A., Mazzarella, J. A., Jordan, J. W., Jr., and Green, E. (1966). Quantitation of QRS and ST segment responses to exercise. American Heart fournal, 71, 455.

Davies, C. T. M., Kitchin, A. H., Knibbs, A. V., and Neilson, J. M. (I97I). Computer quantitation of ST segment response to graded exercise in untrained and trained normal subjects. Cardiovascular Research, 5, 201.

Ewing, D. J., Irving, J. B., Kerr, F., Wildsmith, J. A. W., and Clarke, B. F. (1974). Cardiovascular responses to sustained handgrip in normal subjects and in patients with diabetes mellitus: a test of autonomic function. Clinical Science, 46, 295. 
Karlefors, T. (1966). Exercise tests in male diabetics. I. Electrocardiographic study. Acta Medica Scandinavica, 180, Suppl. 449. 3.

Kitchin, A. H., and Neilson, J. M. (1972). The T wave of the electrocardiogram during and after exercise in normal subjects. Cardiovascular Research, 6, 143.

Master, A. M., Friedman, R., and Dack, S. (1942). The electrocardiogram after standard exercise as a functional test of the heart. American Heart fournal, 24, 777.

Master, A. M., and Rosenfeld, I. (196I). Criteria for the clinical application of the 'two-step' exercise test: observation of false-negative and false-positive responses. Fournal of the American Medical Association, 178, 283.

Neilson, J. M. M., Davies, C. T. M., and Kitchin, A. H. (1968). Method for recording electrocardiographic waveform changes continuously. British Heart fournal, 30, 872.

Oliver, M. F., Samuel, E., Morley, P., Young, G. B., and Kapur, P. L. (1964). Detection of coronary-artery calcification during life. Lancet, I, 891.
Rose, G. A., and Blackburn, H. (1968). Cardiovascular Survey Methods. World Health Organization, Geneva.

Schaefer, H., and Haas, H. G. (1962). Electrocardiography. In Handbook of Physiology, section 2, vol. I, pp. 387 and 389. Ed. by W. E. Hamilton and P. Dow. American Physiological Society, Washington, D.C.

Wheeler, T., and Watkins, P. J. (1973). Cardiac denervation in diabetes. British Medical fournal, 4, 584.

Yu, P. N. G., and Soffer, A. (1952). Studies of electrocardiographic changes during exercise (modified double twostep test). Circulation, 6, 183.

Requests for reprints to Dr. I. W. Campbell, Diabetic and Dietetic Department, The Royal Infirmary, Edinburgh EH3 9YW. 